\title{
The association between ultraviolet $B$ irradiance, vitamin $D$ status and incidence rates of type 1 diabetes in 51 regions worldwide
}

\author{
S. B. Mohr • C. F. Garland • E. D. Gorham • \\ F. C. Garland
}

Received: 20 September 2007 / Accepted: 3 April 2008 / Published online: 12 June 2008

(C) Springer-Verlag 2008

\begin{abstract}
Aims/hypothesis This study is an analysis of the relationship between ultraviolet $B$ (UVB) irradiance, the primary source of circulating vitamin $\mathrm{D}$ in humans, and age-standardised incidence rates of type 1 diabetes mellitus in children, according to region of the world.

Methods The association of UVB irradiance adjusted for cloud cover to incidence rates of type 1 diabetes in children aged $<14$ years during 1990-1994 in 51 regions worldwide was assessed using multiple regression. Incidence data were obtained from the Diabetes Mondial Project Group.

Results Incidence rates were generally higher at higher latitudes $\left(R^{2}=0.25, p<0.001\right)$. According to multiple regression, UVB irradiance adjusted for cloud cover was inversely associated with incidence rates $(p<0.05)$, while per capita health expenditure $(p<0.004)$ was positively associated (overall $R^{2}=0.42, p<0.0001$ ).

Conclusions/interpretation An association was found between low UVB irradiance and high incidence rates of type 1 childhood diabetes after controlling for per capita health expenditure. Incidence rates of type 1 diabetes approached zero in regions worldwide with high UVB irradiance, adding new support to the concept of a role of vitamin D in reducing the risk of the disease.
\end{abstract}

Keywords Epidemiology · Type 1 diabetes .

Ultraviolet rays · Vitamin D

S. B. Mohr • C. F. Garland $(\bowtie) \cdot$ E. D. Gorham • F. C. Garland Department of Family and Preventive Medicine,

University of California San Diego,

9500 Gilman Drive, Mail Code 0631C,

La Jolla, CA 92093-0631, USA

e-mail: cgarland@ucsd.edu

\author{
Abbreviations \\ DiaMond Diabetes Mondial Project Group \\ $1,25(\mathrm{OH})_{2} \mathrm{D} \quad 1,25$-hydroxyvitamin D \\ 25(OH)D 25-hydroxyvitamin D \\ UVB ultraviolet B \\ VDR vitamin D receptor
}

\section{Introduction}

About 15,000 new cases of type 1 diabetes mellitus are diagnosed each year in the USA, making it the second most common chronic disease in children after asthma [1]. It has been estimated that $1,500,000$ people have type 1 diabetes in the USA [1]. Type 1 diabetes is an autoimmune disease that results from the destruction of insulin-producing beta cells in the pancreas [2]. Although it is acknowledged to be an autoimmune disease [2], the causes of type 1 diabetes are still considered to be unknown.

Globally, there is 350 -fold range of age-standardised incidence rates of the disease, from an average of 0.1 per 100,000 in males $<14$ years of age in China [3] to 37 per 100,000 in boys $<14$ years in Finland [3]. The pattern follows a latitudinal gradient that is the inverse of the global distribution of ultraviolet B (UVB) irradiance. Exposure of the skin to sunlight is the source of $80-95 \%$ [4] of circulating vitamin $\mathrm{D}$ and its metabolites, so availability and intensity of sunlight, which are highly related to latitude, are strong correlates of the principal circulating vitamin $\mathrm{D}$ metabolite in the serum, 25-hydroxyvitamin D $[25(\mathrm{OH}) \mathrm{D}]$. This study explores the possible association between UVB irradiance in 51 regions worldwide and incidence rates of type 1 diabetes in children. 


\section{Methods}

Data sources Age-standardised incidence rates of type 1 diabetes mellitus were obtained for 51 world regions for 1990-1994 by the Diabetes Mondial Project Group (DiaMond) [3]. The rates were standardised using the direct method [3]. Sources of data on UVB irradiance adjusted for cloud cover and per capita health expenditure have been described elsewhere [5].

Statistical analysis Age-standardised incidence rates for all regions worldwide were plotted by latitude, and the best fit to the data points was obtained using a polynomial trend line. Multiple linear regression was used to examine the association of solar UVB irradiance adjusted for cloud cover with annual incidence rates of type 1 diabetes in males $<14$ years of age, while controlling for per capita health expenditure. Complete data on all variables were available for 51 world regions, and these regions were included in the multiple regression analysis (Table 1). All analyses were performed using JMP 5.1.2 (SAS Institute, Cary NC, USA).

\section{Results}

Incidence rates of type 1 diabetes mellitus tended to be higher at higher latitudes in both hemispheres $\left(R^{2}\right.$ for latitude $=0.25$, $p<0.0001$; Fig. 1). In the multivariate regression model, UVB irradiance adjusted for cloud cover was negatively associated with incidence rates $(p=0.05)$, while per capita health expenditure was positively associated $(p<0.004$; overall $R^{2}=0.42, p<0.0001$; Table 1 ).

\section{Discussion}

Incidence rates were higher in regions that were more distant from the equator, where UVB irradiance is lower, than in those closer to the equator, where UVB irradiance is much higher. UVB induces vitamin D photosynthesis in the skin, and is the principal source of circulating vitamin D and 25(OH)D [4]. As a sensitivity analysis, a model was also performed that included only cloud-adjusted UVB irradiance. The association was similar, although the coefficient of determination was lower $\left(R^{2}=0.30, p<0.001\right)$.

The association of UVB irradiance with risk of type 1 diabetes that was observed in the present study is consistent with the results of previous studies of oral intake of vitamin $\mathrm{D}$ and risk of type 1 diabetes [6-8]. In Finland, a birthcohort study was undertaken by Hypponen et al. of 10,366 children who were born in 1966 and followed through to 1997 , with the primary outcome being a diagnosis of type 1 diabetes [6]. The study found that children who had oral vitamin D intake of $50 \mu \mathrm{g}(2,000 \mathrm{IU}) /$ day had a lower risk of developing type 1 diabetes (RR 0.22 , 95\% CI 0.12-0.75) compared with children who consumed less than this amount. This is the only observational study in which serum $25(\mathrm{OH}) \mathrm{D}$ was measured in individuals.

Two other studies evaluated the association of use of either a vitamin D supplement or cod liver oil with estimates of risk of type 1 diabetes [7, 8], but did not measure serum $25(\mathrm{OH}) \mathrm{D}$ levels or intake of vitamin $\mathrm{D}$ in their study individuals. A European multi-centre casecontrol study (EURODIAB) reported that vitamin D supplementation in infancy was associated with reduced incidence of type 1 diabetes (OR $0.67,95 \%$ CI $0.53-0.86$ ) [7]. The favourable association with vitamin D persisted after adjustment for birthweight, duration of breast feeding, maternal age and study centre [7]. Another case-control study reported that use of cod liver oil during infancy was associated with lower risk of type 1 diabetes (OR 0.74; 95\% CI 0.56-0.99) [8], although no association was found with vitamin D supplements. Neither study determined whether the children were deficient in serum $25(\mathrm{OH}) \mathrm{D}$ or had low vitamin D intake at baseline.

Two observational studies found a higher risk of type 1 diabetes in children whose mothers had low oral intake of vitamin D during pregnancy: the EURODIAB study found that children whose mothers consumed vitamin D supplements during pregnancy had a lower risk of type 1 diabetes

Table 1 Multiple regression analysis of solar UVB irradiance and per capita health expenditure in association with age-standardised type 1 diabetes incidence rates in 51 regions, 2002

\begin{tabular}{|c|c|c|c|c|}
\hline Variable & Coefficient & SE & $\mathrm{t}$ & $p$ value \\
\hline Solar UVB irradiance ${ }^{a}$ & -0.6831 & 0.3396 & -2.01 & 0.05 \\
\hline Per capita health expenditure (US\$) ${ }^{\mathrm{b}}$ & 0.0031 & 0.0011 & 3.01 & 0.004 \\
\hline Intercept & 10.2239 & 3.4801 & 2.94 & 0.005 \\
\hline
\end{tabular}

$R^{2}=0.42, p<0.0001$

${ }^{a} \mathrm{~W} / \mathrm{m}^{2}$ at vernal equinox, adjusted for mean proportion of sky covered by clouds. Calculated from a standard algorithm [5, 47] based on data for population centroids. For source of centroids see [47]

${ }^{\mathrm{b}}$ For source see [48] 


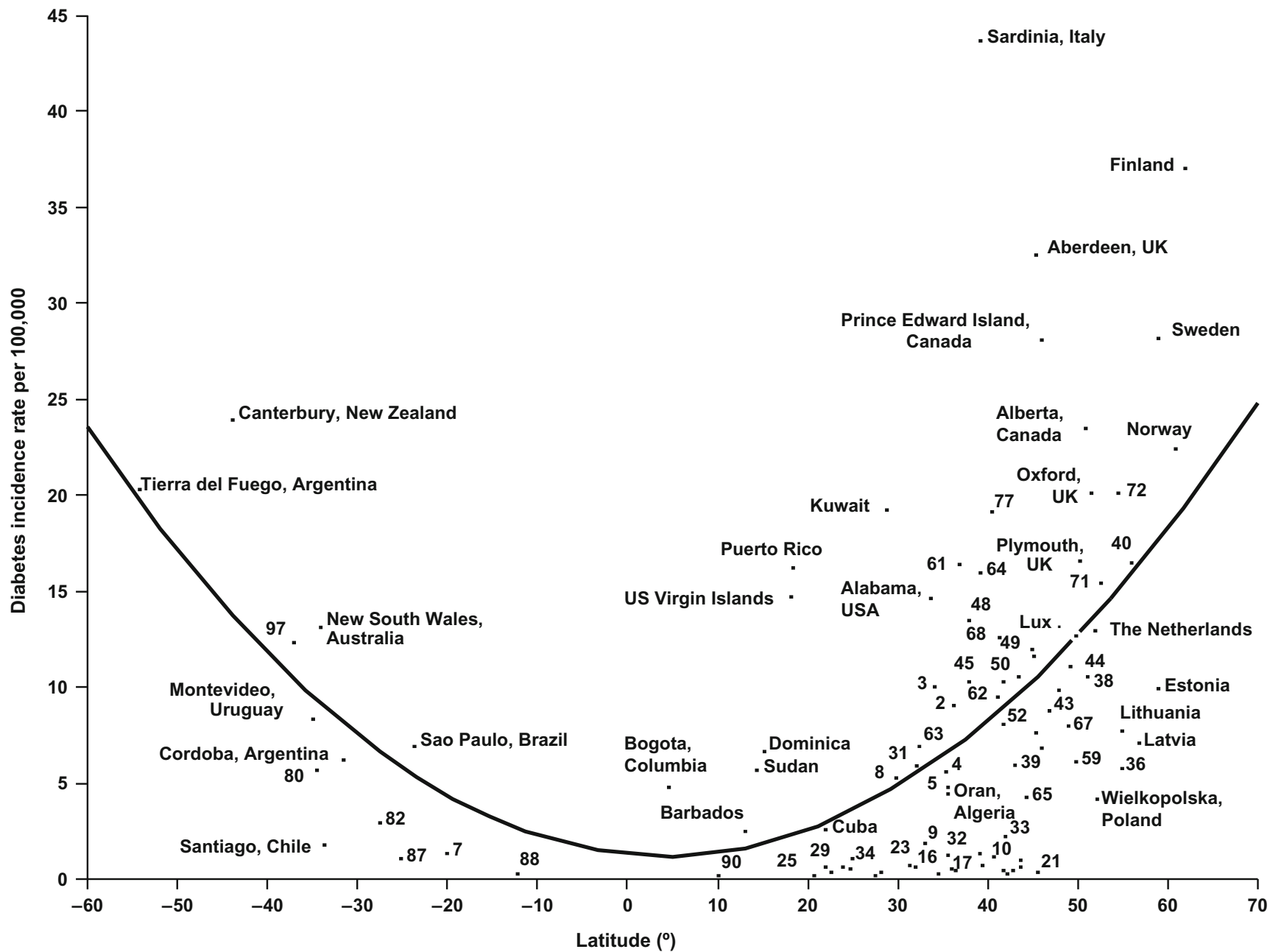

Fig. 1 Age-standardised incidence rates of type 1 diabetes per 100,000 boys $<14$ years of age, by latitude, in 51 regions worldwide, 2002. Data points are shown by dots; names shown adjacent to the dots denote location, where space allows. Where space was limited, numerical codes (below) designate location. Source: data from WHO DiaMond [3]. Lux., Luxembourg. Numerical codes for areas: 2. Beja, Tunisia; 3. Gafsa, Tunisia; 4. Kairoan, Tunisia; 5. Monastir, Tunisia; 7. Mauritius; 8. Wuhan, China; 9. Sichuan, China; 10. Huhehot, China; 16. Nanjing, China; 17. Jinan, China; 21. Harbin, China; 23. Changsha, China; 25. Hainan, China; 29. Hong Kong, China; 31. Israel; 32. Chiba, Japan; 33. Hokkaido, Japan; 34. Okinawa, Japan; 36. Novosibirsk, Russia; 38. Antwerp, Belgium; 39. Varna, Bulgaria; 40. Denmark; 43. France; 44. Baden, Germany; 45. Attica, Greece; 48. Sicily, Italy; 49. Pavia, Italy; 50. Marche, Italy; 52. Lazio, Italy; 59. Krakow, Poland; 61. Algarve, Portugal; 62. Coimbra, Portugal; 63.

than those whose mothers did not (OR $0.67,95 \%$ CI $0.53-$ 0.86 ) [9], and a case-control study by Stene and colleagues found that the risk of diabetes in children of mothers who took cod liver oil during pregnancy was lower than in mothers who did not (OR $0.30,95 \%$ CI $0.12-0.75)$ [10]. Neither study measured serum $25(\mathrm{OH}) \mathrm{D}$ in the participants.

In a cohort study in Colorado, intake of vitamin D during the third trimester of pregnancy was assessed in the mothers of 233 children. The children were then followed
Madeira Island, Portugal; 64. Portalegre, Portugal; 65. Bucharest, Romania; 67. Slovakia; 68. Catalonia, Spain; 71. Leicestershire, UK; 72. Northern Ireland, UK; 77. Allegheny, PA, USA; 80. Avellaneda, Argentina; 82. Corrientes, Argentina; 87. Paraguay; 88. Lima, Peru; 90. Caracas, Venezuela; 97. Auckland, New Zealand. Data points not labelled because of space constraints (latitude in degrees, rate per 100,000): 11. Dalian, China (39, 1.1); 12. Guilin, China $(24,0.6) ; 13$. Beijing, China (40, 0.7); 14. Shanghai, China (32. 0.7); 15. Chang Chun, China (44, 0.6); 18. Jilin, China (43, 0.4); 19. Shenyang, China (42, 0.4); 20. Lanzhou, China (36, 0.5); 22. Nanning, China $(23,0.3)$; 24. Zhengzhou, China $(35,0.2) ; 26$. Tie Ling, China $(42,0.2) ; 27$. Zunyi, China (28, 0.1); 28. Wulumuqi, China (44, 0.9); 35. Karachi, Pakistan $(25,0.5) ; 37$. Austria $(48,9.8) ; 46$. Hungary $(47,8.7) ; 51$. Turin, Italy $(45,11.9)$; 53 . Lombardia, Italy $(46,7.6)$; 66. Slovenia $(46,6.8)$; 79. Chicago, IL, USA $(42,10.2) . R^{2}=0.25, p<0.001$

for an average of 4 years [11]. Maternal intake of vitamin D from food had a protective effect against the appearance of islet cell autoantibodies (multiple-adjusted HR 0.37, 95\% CI 0.17-0.78). Such antibodies are associated with the development of type 1 diabetes [12]. Another study reported lower incidence rates of type 1 diabetes in association with higher ultraviolet radiation in Australia [13].

Some findings from previous research appear to be inconsistent with the hypothesis regarding an overall 
association of vitamin D deficiency with risk. For example, in the three Nordic countries that cover a wide geographical area and range of latitudes (Norway, Finland and Sweden), the more northern regions of each country do not receive sufficient solar UVB to make vitamin D during winter [14]. Yet the within-country variation in incidence of type 1 diabetes is generally reversed in comparison with what would be expected on the basis of solar irradiance, with lower rates in the north [15].

While the reversal of the north-south gradient within these countries is paradoxical, there are some factors that may be relevant to understanding it. The northern parts of these countries are typically more rural, subsistence or commercial fishing-based and agrarian than the middle and southern regions, where the largest metropolitan areas are located [15]. Intake of fatty fish, such as herring, may be higher in regions where fishing is a major activity. Intake of fatty fish is associated with substantial increases in serum 25(OH)D [16]. The effect of supplementation with vitamin $\mathrm{D}$ in northern regions or seasonally high intake of foods containing large amounts of vitamin $\mathrm{D}$ in these areas may also be a factor. In a northern area of Norway $\left(69^{\circ} \mathrm{N}\right)$, high intake of cod liver oil substantially reduced the expected seasonality of serum 25(OH)D in the population [17]. Despite consumption of foods containing substantial amounts of vitamin $\mathrm{D}$, serum $25(\mathrm{OH}) \mathrm{D}$ levels generally are lower in residents of northern areas of Norway [18] and Finland [19]. Consistent with this finding, one more recent study in Sweden reported that incidence rates of type 1 diabetes increased with increasing latitude [20], suggesting that the apparent reversal in incidence rates compared with expectation may be disappearing with time there.

The association of low levels of UVB irradiance or vitamin D with type 1 diabetes is consistent with the physiology of vitamin $\mathrm{D}$ metabolites that are known to be powerful immunomodulatory agents [21-25]. There are several known mechanisms by which vitamin $\mathrm{D}$ metabolites, particularly 1,25 -hydroxyvitamin $\mathrm{D}\left[1,25(\mathrm{OH})_{2} \mathrm{D}\right]$, modulate the function of antigen-presenting cells and induce dendritic cells with a tolerogenic phenotype [21, 23-25].

Experiments have shown that vitamin D receptor (VDR) ligands induce dendritic cells to acquire tolerogenic properties that favour the induction of regulatory rather than effector T cells in vitro and in vivo [23]. Analysis of the molecular profile of dendritic cells cultured in the presence of $1,25(\mathrm{OH})_{2} \mathrm{D}_{3}$ showed considerable suppression of the expression of nuclear factor-kappaB family member Re1B [24]. This substance plays an essential role in differentiation and maturation of dendritic cells. The mechanism of this effect involves direct binding of VDR/ retinoid-X-receptor alpha to a defined region of the relB promoter, and assembly of a negative regulatory complex containing HDAC3, HDAC1, SMRT and other factors [24].
Exposure of human blood myeloid dendritic cells and plasmacytoid dendritic cells to $1,25(\mathrm{OH})_{2} \mathrm{D}_{3}$ upregulates production of CCL22, a chemokine that attracts regulatory $\mathrm{T}$ cells [25], although production of CCL17, the other CCR4 ligand, is reduced [23]; $1,25(\mathrm{OH})_{2} \mathrm{D}_{3}$ also decreases production of IL-12 [25]. As a result of the above tolerogenic actions, and possibly others not yet fully characterised, vitamin $\mathrm{D}$ metabolites such as $1,25(\mathrm{OH})_{2} \mathrm{D}_{3}$ have considerable potential to reduce the severity of autoimmune diseases, such as autoimmune type 1 diabetes [21], and have been used in this role [21]. This could reduce the intensity of the autoimmune response to insulin that is thought to be a critical component of the aetiology of type 1 diabetes [22].

Previous research $[3,6-13]$ and the results of the present study suggest that many cases of type 1 diabetes might be prevented by raising the serum 25(OH)D levels of infants and children living at high latitudes to levels that are present in the tropics. Such levels are in the range of 125 $150 \mathrm{nmol} / 1(50-60 \mathrm{ng} / \mathrm{ml})$ [26]. These serum 25(OH)D levels have been observed in lifeguards in the United States during the summer [27]. They are markedly higher than the levels in children in the general US population in the northeast, where the nominal range is $48-88 \mathrm{nmol} / \mathrm{l}(19-35 \mathrm{ng} /$ $\mathrm{ml}$ ) [28]. In these US children, blood drawn during winter was associated with higher risk of vitamin D deficiency than during summer (OR 3.55, 95\% CI 2.3-5.0) as was being black compared with white (OR 14.2, 95\% CI 8.523.5) [29]. Data from this study suggest that the typical range of $25(\mathrm{OH}) \mathrm{D}$ in these children during winter may be approximately 30-60 nmol/1 (12-24 ng/ml). Efforts at prevention would require raising the overall serum level of 25(OH)D in infants and children in winter to approximately $125 \mathrm{nmol} / \mathrm{l}(50 \mathrm{ng} / \mathrm{ml})$, a difference of $65-95 \mathrm{nmol} /$ 1 (26-38 ng/ml) compared with usual levels.

Since serum 25(OH)D increases by $1 \mathrm{ng} / 2.5 \mu \mathrm{g}$ (100 IU) of oral intake of vitamin $\mathrm{D}$ [30], this would suggest providing supplementation at a level of $\geq 50 \mu \mathrm{g}(2,000 \mathrm{IU}) /$ day of vitamin D. Oral supplementation of children has a current upper limit of $25 \mu \mathrm{g}(1,000 \mathrm{IU}) /$ day according to the National Academy of Sciences, Institute of Medicine [28]. It would be necessary to add the equivalent of $40-70 \mu \mathrm{g}$ $(1,500-2,800 \mathrm{IU}) /$ day of vitamin $\mathrm{D}$ from solar UVB irradiance to reach the $125 \mathrm{nmol} / \mathrm{l}(50 \mathrm{ng} / \mathrm{ml})$ serum level appropriate for substantial reduction in the risk of type 1 diabetes, according to the above relationship [30].

Since vitamin $\mathrm{D}_{3}$ is synthesised at a rate of approximately $25 \mu \mathrm{g}(1,000 \mathrm{IU}) / \mathrm{min}$ when the sun is $60^{\circ}$ or more above the horizon [31], this could be achieved with approximately $5 \mathrm{~min}$ of exposure of an infant or child to sunlight between 11:00 and 13:00 hours during the summer at mid-latitudes, and 10-12 $\mathrm{min}$ during the spring and autumn. The effectiveness of these measures in maintaining 
at least $50-60 \mathrm{ng} / \mathrm{ml}$ but $<90 \mathrm{ng} / \mathrm{ml}$ of serum $25(\mathrm{OH}) \mathrm{D}$ should be monitored with annual testing of the blood in early spring (February or March), when serum 25(OH)D levels are lowest [31]. Serum levels of 25(OH)D in the range $125-250 \mathrm{nmol} / 1(50-100 \mathrm{ng} / \mathrm{ml})$ have been determined to be safe according to comprehensive systematic reviews $[30,32]$. Brief exposure to sunlight in the range needed to achieve the benefit of vitamin D on risk of type 1 diabetes is not likely to increase risk of skin cancer, and some studies suggest a lower risk and severity of melanoma in association with moderate solar exposure [33-34].

Strengths This study has been the first to examine worldwide incidence rates of type 1 diabetes mellitus according to UVB irradiance. The regression model accounted for $42 \%$ of the variation in incidence rates. The regression analysis allowed assessment of the independent contribution of UVB irradiance while controlling for per capita health expenditure [35], a surrogate measure of each region's economic development and medical care system. This covariate may serve as a proxy for the availability of medical care that could support diagnosis of type 1 diabetes.

Per capita healthcare expenditure was controlled for because regions located near the equator had higher levels of UVB irradiance and tended to have lower per capita healthcare expenditure [35]. Regions with low per capita healthcare expenditure may lack the resources and healthcare infrastructure to properly diagnose cases of type 1 diabetes [36]. This may result in under-reporting of type 1 diabetes in tropical regions [36], while at the same time inflating an inverse association between UVB irradiance and incidence of type 1 diabetes. Since the association with UVB irradiance persisted after adjustment for per capita health expenditure, it is unlikely that the observed variation was a solely a product of variation between world regions in socioeconomic status or in the likelihood of diagnostic ascertainment of type 1 diabetes. In addition, this covariate is also likely to be a proxy measure of exposures associated with the Western lifestyle (physical inactivity and a high-fat and high-refined sugar diet) that is typically present in more affluent world regions [37]. The association between low UVB irradiance and high incidence of type 1 diabetes is not likely to be caused by confounding by differences in medical care or exposures characteristic of the Western lifestyle.

Another advantage of this study is that type 1 diabetes is a well-defined disease, whose diagnosis is largely based on whether an individual needs to inject insulin. The study was based on data derived from a larger number of cases, 19,164 , than any previous study of environmental factors pertinent to type 1 diabetes.

Limitations A question when trying to generalise from observations of groups to individuals is whether it is ap- propriate to impute the findings for a group to the individuals in it [38]. This was first described for behavioural studies, but may be applicable to measures of precursors of disease. The possibility that characteristics that apply to a group may not apply to the individuals in it should be considered when evaluating this or any analysis based on groups.

This was a study of populations rather than individuals. Findings that apply to aggregates may not apply to individuals. For example, all individuals living in areas of high UVB irradiance may not have high exposure to UVB. This can result from urbanisation and industrialisation. On the other hand, regional solar UVB irradiance is likely to affect a broad range of individuals, and the association was present despite the possible misclassification of exposure. Systematic assessment errors may produce more pronounced errors in analyses of group-level exposure measures that in analysis of individual-level exposures, increasing the possibility of bias [38]. It has also been reported that random misclassification in studies of aggregate measures does not always result in bias toward the null [38].

Ecological studies also may include interactions, including the possibility of effect modification [38]. For example, absorption of UVB irradiance by clothing could not be measured in the present study, yet it is possible that the association of UVB with incidence rates of type 1 diabetes could have been influenced by the type of clothing worn. Since there was no systematic source of information available on clothing characteristics according to world region, it was not possible to examine this possible interaction. There are several biases that should be evaluated when assessing ecological studies [38]. These include within-group biases, confounding by group, and effect modification by group [38]. These may differ somewhat from biases typically encountered in studies of individuals.

It should be noted as a limitation that the inverse association that was observed between UVB irradiance and incidence of type 1 diabetes could have an explanation in an effect of UVB irradiance other than its probable influence on vitamin D biosynthesis. For example, UV irradiance can reduce the concentration of many pathogens on environmental surfaces, such as Coxsackie B virus [39, 40], and some airborne pathogens [41]. While this effect has been shown mainly for UV lamps that emit both UVB and ultraviolet C [41], such an effect of solar UVB is possible. Solar UVB sterilisation of surfaces or air could interrupt transmission of a pathogenic organism potentially involved in the aetiology of type 1 diabetes, including Coxsackie B [40] and other viruses [42].

Regions with higher UVB irradiance also tended to have higher total solar irradiance, and were generally warmer, possibly reducing the length of survival of pathogens on environmental surfaces. Warmer temperature is also associated with higher frequency of open-air physical activity [43]. 
Wearing clothing that reduces solar exposure causes lower serum 25(OH)D levels [44]. For example, serum 25 $(\mathrm{OH}) \mathrm{D}$ levels were low in mothers $(34 \mathrm{nmol} / \mathrm{l})$ and neonates (20 nmol/l) in Kuwait, where many women wear traditional clothing that reduces solar exposure [44]. Despite being higher than expected (Fig. 1), incidence rates in Kuwait were still low compared with European countries. Since children are not generally covered by clothing even in traditional Muslim countries, some degree of recovery from low serum 25(OH)D levels as neonates would be expected during childhood. Possibly because of this, incidence rates of type 1 diabetes in children were similar to expectation based on latitude in other countries where clothing that limits exposure to the sun is worn by adults (Fig. 1).

A further limitation was the lack of data regarding vitamin D intake from foods, supplements or fortification, which was not available from the WHO. On the other hand, oral intake generally plays a small role in serum $25(\mathrm{OH}) \mathrm{D}$ levels [4].

Studies of this type are generally hypothesis generating, rather than definitive. They are often a source of variables to be investigated with other methods. However, the diverse geographical distribution of populations in world regions with different levels of UVB irradiance provides a natural experiment on a large scale.

Finally, several laboratory studies have been consistent with the existence of an association between murine vitamin $\mathrm{D}$ deficiency and risk of type 1 diabetes. Mathieu et al. reported that administration of $5 \mu \mathrm{g} / \mathrm{kg}$ of 1,25 $(\mathrm{OH})_{2} \mathrm{D}$, the most active vitamin $\mathrm{D}$ metabolite, reduced incidence of autoimmune diabetes in non-obese diabetic (NOD) mice from $56 \%$ to $8 \%$ up to day 200 of the animals' lives [45]. The dose was well tolerated by the mice, including normal growth rates and serum calcium levels. Zella et al. reported that addition of $50 \mathrm{ng} /$ day of 1,25 $(\mathrm{OH})_{2} \mathrm{D}$ to the diet of NOD mice prevented diabetes up to day 200 of the animals' lives [46].

Conclusions This is the first study, to the authors' knowledge, to analyse the pattern of incidence of diabetes in the world according to latitude and solar ultraviolet irradiance. This natural experiment found that $25 \%$ of the variation in incidence rates among regions of the world can be accounted for on the basis of latitude, and that a substantial proportion can be accounted for on the basis of solar UVB irradiance and percentage cloud cover, the main atmospheric determinants of vitamin D biosynthesis. The association persisted despite controlling for per capita healthcare expenditures. The results support previous research that has reported a higher risk of diabetes in children whose mothers had poor vitamin D status, or in the children themselves.

The results of this study, combined with previous research, may have considerable importance for preventive medicine. No tool has been available to physicians to prevent childhood type 1 diabetes until now. The low incidence rate of type 1 diabetes in regions close to the equator indicates that there is potential for substantial reduction in incidence rates at higher latitudes.

The choice of an appropriate dosage is an important issue. A serum 25(OH)D level of 125-135 nmol/1 (50$60 \mathrm{ng} / \mathrm{ml}$ ) has been reported in lifeguards [27], and is probably similar to the level that would be predicted in palaeolithic humans in many regions on an evolutionary basis, so it may be a reasonable serum target for use in reduction of incidence of childhood type 1 diabetes.

While rickets can be prevented with far smaller doses, a level needed to prevent diabetes would require intake, by children aged $\geq 1$ year, of approximately $25-50 \mu \mathrm{g}(1,000$ 2,000 IU)/day of vitamin $\mathrm{D}_{3}$ [6], an intake associated with major reduction in incidence in Norway. Such intake has no known adverse health effects in adults [28, 30, 32].

Children aged $\geq 1$ year and who are outdoors in sunlight for a few minutes each day may achieve similar serum levels with smaller oral intake. If desired, the serum level of $25(\mathrm{OH}) \mathrm{D}$ can be readily monitored by widely available blood tests. Monitoring can help with choice of an appropriate combination of oral intake and modest sunlight exposure. Pending further research, oral vitamin D intake of infants $<1$ year old should not exceed $6.25 \mu \mathrm{g}$ (250 IU)/day [28]. The vitamin D status of pregnant women generally may be kept within an appropriate range with modest supplementation of 10-15 $\mu \mathrm{g}$ (400-600 IU)/day [28].

Physicians and nutritionists should advise parents that children $\geq 1$ year who live more than approximately $30^{\circ}$ from the equator should consume 25-50 $\mu \mathrm{g}(1,000$ $2,000 \mathrm{IU}$ )/day of vitamin $\mathrm{D}_{3}$, especially during winter, to substantially reduce their risk of childhood type 1 diabetes.

Further epidemiological studies would be desirable on the effect of serum $25(\mathrm{OH}) \mathrm{D}$ levels and oral intake of vitamin $\mathrm{D}$ on incidence of type 1 diabetes. In the meantime, public health action seems warranted, based on evidence gathered to date from many studies. Modest public health actions based on this research are likely to substantially reduce the incidence of type 1 diabetes in children, and should be initiated with appropriate caution, but without further delay.

Acknowledgements This research was supported by a Congressional allocation to the University of Miami Diabetes Research Institute, Miami, FL, through the Department of the Navy, Bureau of Medicine and Surgery, under Work Unit No. 60126. The views expressed in this report are those of the authors and do not represent an official position of the Department of the Navy, Department of Defense or the US Government.

Duality of interest The authors declare that there is no duality of interest associated with this manuscript. 


\section{References}

1. Eiselein L, Schwartz HJ, Rutledge JC (2004) The challenge of type 1 diabetes mellitus. ILAR J 45:231-236

2. Jahromi MM, Eisenbarth GS (2007) Cellular and molecular pathogenesis of type I diabetes. Cell Mol Life Sci 64:865-872

3. Karvonen M, Viik-Kajander M, Moltchanova E, Libman I, LaPorte R, Tuomilehto J (2000) Incidence of childhood type 1 diabetes worldwide. Diabetes Mondiale (DiaMond) Project Group. Diabetes Care 23:1516-1526

4. Adams JS, Clemens TL, Parrish JA, Holick MF (1982) Vitamin-D synthesis and metabolism after ultraviolet irradiation of normal and vitamin-D-deficient subjects. N Engl J Med 306:722-725

5. Mohr SB, Garland CF, Gorham ED, Grant WB, Garland FC (2007) Is ultraviolet $\mathrm{B}$ irradiance inversely associated with incidence rates of endometrial cancer: an ecological study of 107 countries. Prev Med 45:327-331

6. Hypponen E, Laara E, Reunanen A, Jarvelin MR, Virtanen SM (2001) Intake of vitamin D and risk of type 1 diabetes: a birthcohort study. Lancet 358:1500-1503

7. EURODIAB Substudy 2 Study Group (1999) Vitamin D supplement in early childhood and risk for Type I (insulindependent) diabetes mellitus. Diabetologia 42:51-54

8. Stene LC, Joner G (2003) Use of cod liver oil during the first year of life is associated with lower risk of childhood-onset type 1 diabetes: a large, population-based, case-control study. Am J Clin Nutr 78:1128-1134

9. Dahlquist GG, Patterson C, Soltesz G (1999) Perinatal risk factors for childhood type 1 diabetes in Europe. The EURODIAB Substudy 2 Study Group. Diabetes Care 22:1698-1702

10. Stene LC, Barriga K, Norris JM et al (2004) Perinatal factors and development of islet autoimmunity in early childhood: the diabetes autoimmunity study in the young. Am J Epidemiol 160:3-10

11. Fronczak CM, Baron AE, Chase HP et al (2003) In utero dietary exposures and risk of islet autoimmunity in children. Diabetes Care 26:3237-3242

12. Stene LC, Ulriksen E, Magnus P, Joner G (2000) Use of cod liver oil during pregnancy associated with lower risk of Type I diabetes in the offspring. Diabetologia 43:1093-1098

13. Staples JA, Ponsonby AL, Lim LL, McMichael AJ (2003) Ecologic analysis of some immune-related disorders, including type 1 diabetes, in Australia: latitude, regional ultraviolet radiation, and disease prevalence. Environ Health Perspect 111:518-523

14. Ponsonby AL, Lucas RM, van der Mei IA (2005) UVR, vitamin D and three autoimmune diseases-multiple sclerosis, type 1 diabetes, rheumatoid arthritis. Photochem Photobiol 81:1267-1275

15. Akerblom HK, Reunanen A (1985) The epidemiology of insulindependent diabetes mellitus (IDDM) in Finland and in northern Europe. Diabetes Care 8:10-16

16. Burgaz A, Akesson A, Oster A, Michaelsson K, Wolk A (2007) Associations of diet, supplement use, and ultraviolet $\mathrm{B}$ radiation exposure with vitamin D status in Swedish women during winter. Am J Clin Nutr 86:1399-1404

17. Brustad M, Edvardsen K, Wilsgaard T, Engelsen O, Aksnes L, Lund E (2007) Seasonality of UV-radiation and vitamin D status at 69 degrees north. Photochem Photobiol Sci 6:903-908

18. Brustad M, Alsaker E, Engelsen O, Aksnes L, Lund E (2004) Vitamin D status of middle-aged women at $65-71$ degrees $\mathrm{N}$ in relation to dietary intake and exposure to ultraviolet radiation. Public Health Nutr 7:327-335

19. Kokkonen J, Koivisto M, Kirkinen P (1983) Seasonal variation in serum-25-OH- $\mathrm{D}_{3}$ in mothers and newborn infants in northern Finland. Acta Paediatr Scand 72:93-96

20. Nystrom L, Dahlquist G, Ostman J et al (1992) Risk of developing insulin-dependent diabetes mellitus (IDDM) before
35 years of age: indications of climatological determinants for age at onset. Int J Epidemiol 21:352-358

21. Adorini L (2002) Immunomodulatory effects of vitamin D receptor ligands in autoimmune diseases. Int Immunopharmacol 2:1017-1028

22. Kent SC, Chen Y, Bregoli L et al (2005) Expanded T cells from pancreatic lymph nodes of type 1 diabetic subjects recognize an insulin epitope. Nature 435:224-228

23. Penna G, Amuchastegui S, Giarratana N et al (2007) 1,25Dihydroxyvitamin $\mathrm{D}_{3}$ selectively modulates tolerogenic properties in myeloid but not plasmacytoid dendritic cells. J Immunol 178:145-153

24. Griffin MD, Dong X, Kumar R (2007) Vitamin D receptormediated suppression of Re1B in antigen presenting cells: a paradigm for ligand-augmented negative transcriptional regulation. Arch Biochem Biophys 460:218-226

25. Adorini L, Giarratana N, Penna G (2004) Pharmacological induction of tolerogenic dendritic cells and regulatory $\mathrm{T}$ cells. Semin Immunol 16:127-134

26. Chailurkit LO, Rajatanavin R, Teerarungsikul K, Ongphiphadhanakul B, Puavilai G (1996) Serum vitamin D, parathyroid hormone and biochemical markers of bone turnover in normal Thai subjects. J Med Assoc Thai 79:499-504

27. Haddad JG, Chyu KJ (1971) Competitive protein-binding radioassay for 25-hydroxycholecalciferol. J Clin Endocrinol Metab 33:992-995

28. National Academy of Sciences-Institute of Medicine-Food and Nutrition Board-Standing Committee on the Scientific Evaluation of Dietary Reference Intakes (1997) Dietary reference intakes for calcium, phosphorus, magnesium, vitamin D and fluoride. National Academy Press, Washington DC

29. Chen TC, Chimeh F, Lu Z et al (2007) Factors that influence the cutaneous synthesis and dietary sources of vitamin D. Arch Biochem Biophys 460:213-217

30. Vieth R (1999) Vitamin D supplementation, 25-hydroxyvitamin D concentrations, and safety. Am J Clin Nutr 69:842-856

31. Webb AR, Kline L, Holick MF (1988) Influence of season and latitude on the cutaneous synthesis of vitamin $\mathrm{D}_{3}$ : exposure to winter sunlight in Boston and Edmonton will not promote vitamin $\mathrm{D}_{3}$ synthesis in human skin. J Clin Endocrinol Metab 67:373-378

32. Hathcock JN, Shao A, Vieth R, Heaney R (2007) Risk assessment for vitamin D. Am J Clin Nutr 85:6-18

33. Ainsleigh G (1993) Beneficial effects of sun exposure on cancer mortality. Prev Med 22:132-140

34. Berwick M, Armstrong BK, Ben-Porat L et al (2005) Sun exposure and mortality from melanoma. J Natl Cancer Inst 97:195-199

35. World Health Organization (2004) World Health Report 2004 Statistical Annex. Available from: http://www.who.int/whr/2004/ annex/en/index.html, accessed 11 July 2007

36. Menon RK, Sperling MA (2003) Pediatric diabetes. Kluwer, Boston, MA

37. Chaturvedi N, Stephenson JM, Fuller JH (1996) The relationship between socioeconomic status and diabetes control and complications in the EURODIAB IDDM Complications Study. Diabetes Care 19:423-430

38. Rothman KS (1998) Modern epidemiology. Lippincott-Raven, Philadelphia, PA

39. Romanescu G, Pleceas M (1968) Inactivating action of ultraviolet rays on influenza virus and Coxsackie virus. Stud Cercet Inframicrobiol 19:105-112 (in Romanian)

40. Barrett-Connor E (1985) Is insulin-dependent diabetes mellitus caused by Coxsackie virus B infection? A review of the epidemiologic evidence. Rev Infect Dis 7:207-215

41. Riley RL (1977) Ultraviolet air disinfection for protection against influenza. Johns Hopkins Med J 141:29-30 
42. Jun HS, Yoon JW (2003) A new look at viruses in type 1 diabetes. Diabetes Metab Res Rev 19:8-31

43. Suminski RR, Poston WC, Market P, Hyder M, Sara PA (2008) Meteorological conditions are associated with physical activities performed in open-air settings. Int J Biometeorol 52:189-197

44. Molla AM, Al Badawi M, Hammoud MS et al (2005) Vitamin D status of mothers and their neonates in Kuwait. Pediatr Int 47:649-652

45. Mathieu C, Waer M, Laureys J, Rutgeerts O, Bouillon R (1994) Prevention of autoimmune diabetes in NOD mice by 1,25 dihydroxyvitamin $\mathrm{D}_{3}$. Diabetologia 37:552-558

46. Zella JB, McCary LC, DeLuca HF (2003) Oral administration of 1,25-dihydroxyvitamin $\mathrm{D}_{3}$ completely protects NOD mice from insulin-dependent diabetes mellitus. Arch Biochem Biophys 417:77-80

47. Columbia University, Center for International Earth Science Information Network, Gridded Population of the World Database, Version 3 (2000). Available from http://www.ciesin.columbia.edu/ eidata/resource.jsp, accessed 11 May 2008

48. World Health Organization (2001) The World Health Report 2001 statistical annex. WHO publication no. 1242001. WHO, Geneva, p 160 [Table 5. Selected national health accounts indicators for all member states, estimates for 1997 and 1998]. Available from http://www.who.int/whr/2001/en/annex5_en.pdf, accessed 11 May 2008 